\title{
Aplikasi Metode Induced Polarization untuk Mengidentifikasi Akifer di Daerah Sutorejo, Surabaya
}

\author{
Bagas Aryaseta, Dwa Desa Warnana, dan Amien Widodo \\ Jurusan Teknik Geofisika, Fakultas Teknik Sipil dan Perencanaan, Institut Teknologi Sepuluh Nopember (ITS) \\ Jl. Arief Rahman Hakim, Surabaya 60111 Indonesia \\ e-mail:dwa_desa@geofisika.its.ac.id
}

\begin{abstract}
Abstrak-Surabaya merupakan ibukota Jawa Timur yang merupakan pusat perekonomian serta pemerintahan. Ketersediaan air bersih merupakan salah satu permasalahan Surabaya. Pengambilan air tanah yang berlebihan tanpa adanya feedback yang baik akan mengakibatkan terganggunya kesetimbangan air. Salah satu akibat yang dihasilkan adalah penurunan muka air tanah serta adanya intrusi air laut. Salah satu metode untuk mengidentifikasi karakteristik air tanah adalah metode Induced Polarization. Metode ini akan mengukur chargeabilitas bawah permukaan dengan cara mengalirkan arus listrik kedalam tanah. Pengambilan data Induced Polarization dilakukan di daerah Sutorejo. Penampang chargeabilitas selanjutnya akan diinterpretasi dan dianalisis untuk mengidentifikasi perlapisan akifer. Jarak elektroda terkecil yang digunakan adalah 2.5 meter dengan panjang lintasan $80 \mathrm{~m}$. Kedalaman penampang yang dihasilkan adalah 9 meter. Hasil dari penampang chargeabilitas akan dikorelasikan dengan penampang resistivitas. Dari penampang dapat diidentifikasi zona akifer lempung pasiran dan zona lempungan. Akifer lempung pasiran memiliki chargeabilitas rendah $(0.00240-0.302 \mathrm{msec})$ dan resistivitas tinggi (6.81-63.1 ohm.m). Zona lempungan memiliki chargeabilitas tinggi $(0.702-1.30 \mathrm{msec})$ serta resistivitas sedang (0.734-6.81 ohm.m).
\end{abstract}

Kata Kunci- Air Tanah, Akuifer, Chargeability, Induced Polarization, Resistivity

\section{PENDAHULUAN}

$\mathrm{D}$ AERAH Surabaya merupakan daerah perkotaan dengan populasi penduduk sebanyak 2,765 juta jiwa. [1] Kebutuhan air bersih akan meningkat seiring dengan pertumbuhan kota. Sebagian wilayah Surabaya timur tepatnya Gunung Anyar hingga Kenjeran merupakan daerah pesisir. Kawasan Pesisir Surabaya merupakan Kawasan Strategis Ekonomi dengan luas wilayah 521,62 hektare yang terdiri dari dua kecamatan (Kenjeran dan Bulak) dan enam kelurahan dengan panjang garis pantai 8627.80 meter. [2] Sehingga tidak dipungkiri sebagian air sumur di wilayah Surabaya memiliki rasa asin karena salinitas tinggi yang disebabkan adanya asosiasi dengan wilayah pantai.

Penelitian ini dilakukan untuk mengidentifikasi akifer air tanah dengan metode Induced Polarization 2D. Dari penelitian ini diharapkan adanya terlihat jelas suatu perlapisan akuifer. Metode Induced Polarization 2D akan menghasilkan penampang chargeabilitas bawah permukaan. Penampang tersebut akan dibandingkan dengan penampang resistivitas $2 \mathrm{D}$ dan dianalisis untuk melihat dan mengidentifikasi akifer air tanah.

\section{II.TINJAUAN PUSTAKA}

\section{A. Metode Induced Polarization (IP)}

Prinsip metode IP adalah mengalirkan arus listrik kedalam bumi dan mengamati beda potensial yang terjadi setelah arus listrik dihentikan. Pada saat arus diinjeksikan, ion-ion dalam pori-pori batuan akan teridistribusi dari posisi stabil menjadi tidak stabil. Ketika arus diputus, seharusnya beda potensial langsung menjadi nol, akan tetapi pada medium-medium tertentu beda potensial tidak langung menjadi nol dikarenakan medium bersifat seperti kapasitor (menyimpan senergi listrik). Energi listrik masih tersimpan dalam bentuk energi elektrokimia pada fluida elektrolit maupun mineral konduktif pada pori-pori batuan. Jadi setelah arus diputus, ion-ion yang sebelumnya mengalami pengkutuban berangsur-angsur kembali ke keadaan seimbangnya dengan kata lain masih terdapat beda tegangan yang akan meluruh terhadap waktu sampai nilainya menjadi nol. [3]

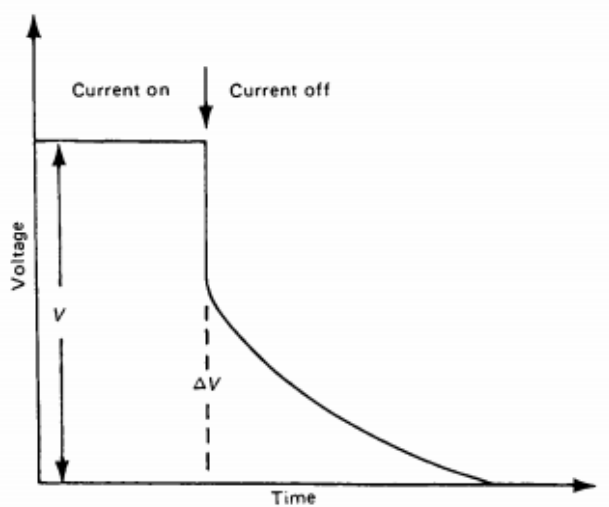

Gambar 1. Peluruhan arus pada batuan yang mengandung mineral logam atau clay

Pengukuran IP dalam time domain dilakukan dengan cara menginjeksikan arus listrik dan kemudian mengukur beda potensial setelah arus dimatikan. Pengukuran nilai beda potensial dilakukan hingga tegangan mencapai nilai nol. Parameter yang diukur adalah tegangan primer $(\mathrm{Vp})$ yaitu 
tegangan ketika arus belum dimatikan dan tegangan sekunder (Vs) yaitu tegangan yang terukur selama waktu peluruhan. Untuk menghitung nilai apparent chargeability (Ma) dilakukan dengan cara membandingkan nlai $\mathrm{Vp}$ dengan nilai rata-rata $\mathrm{Vs}$ yang diperoleh dengan cara mengintegralkan Vs terhadap sampel waktu peluruhan.

$$
M a=\frac{1}{V} \int_{t 1}^{t 2} V(t) d t
$$

Terdapat dua sumber penyebab polarisasi pada batuan. Sumber pertama adalah membrane polarization. Faktor yang mengakibatkan adanya polarisasi pada membrane polarization adalah adanya penyempitan pori-pori pada batuan dan adanya clay. Penyempitan pori-pori akan menyebabkan terhambatnya ion-ion pada batuan sehingga arus akan dapat tersimpan dalam beberapa waktu tertentu. Sedangkan adanya clay menyebabkan terkumpulnya ion-ion positif, hal ini dikarenakan sifat clay yang berupa ion negative. Sumber kedua adalah polarisasi elektroda. Polarisasi elektroda terjadi karena adanya mineral logam dalam pori-pori batuan. Hal ini akan mengakibatkan tertahannya arus listrik ketika melalui pori-pori tersebut. Pada umumnya, akifer air tanah yang mengandung freshwater akan menunjukkan nilai chargeability sebesar $0 \mathrm{msec}$. Apabila akifer tersebut merupakan air asin umumnya akan memiliki nilai chargeability sebesar $0.2 \mathrm{msec}$. [4]

\section{B. Metode Wenner-Schlumberger}

Konfigurasi Wenner-Schlumberger adalah konfigurasi dengan sistem aturan spasi yang konstan dengan catatan faktor pembanding " $\mathrm{n}$ " untuk konfigurasi ini adalah perbandingan jarak antara elektroda arus (AB) dengan potensial (MN). Apabila jarak elektroda potensial MN adalah a maka jarak elektroda AB adalah 2na+a. [5]

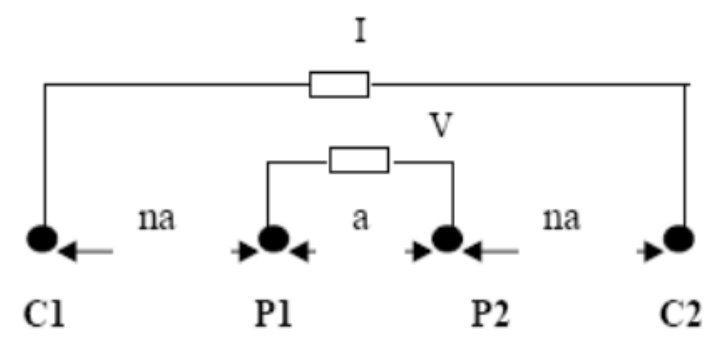

Gambar 2. Konfigurasi Wenner-Schlumberger

\section{METODOLOGI PENELITIAN}

Metodologi penelitian dari penelitian ini adalah dengan melakukan pengukuran geolistrik metode Induced Polarization konfigurasi Wenner-Sclumberger. Hasil penampang 2D metode induced polarization akan dibandingkan dengan metode resistivity. Berikut ini adalah diagram alir yang digunakan.

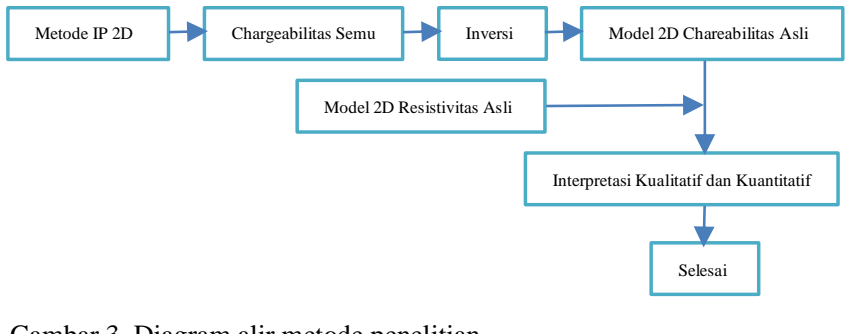

Gambar 3. Diagram alir metode penelitian

\section{HASIL DAN PEMBAHASAN}

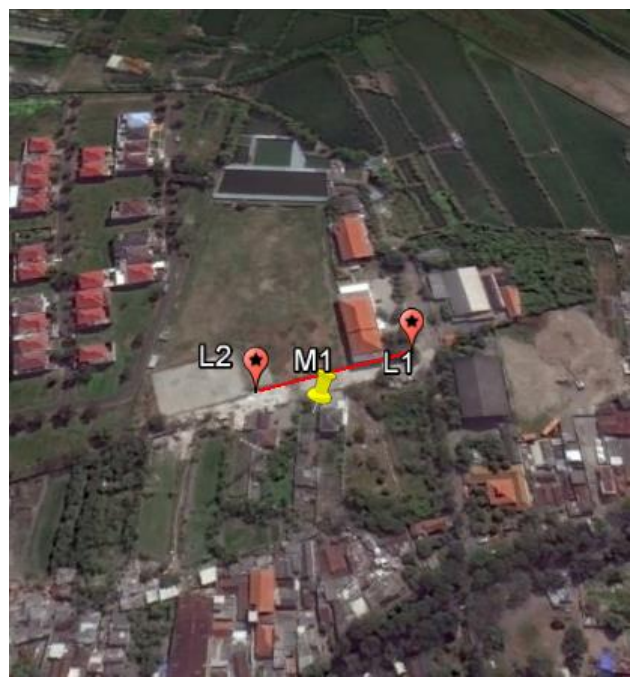

Gambar 4. Lokasi pengukuran IP dan resistivity daerah Sutorejo

Pengukuran IP dan resistivity di daerah Sutorejo (titik L) dilaksanakan pada tanggal 10 Oktober 2016 pada pukul 11.00 WIB sampai 22.00 WIB dengan cuaca mendung. Lokasi pengukuran merupakan tanah alluvial dengan sedikit vegetasi dengan jarak 3 meter terhadap pantai. Bentangan pengukuran sebesar $80 \mathrm{~m}$ dengan jarak elektroda terkecil (a) sebesar 2.5 meter dan faktor spasi (n) sebanyak 10. Sehingga didapatkan penampang dengan kedalaman 9 meter.

Hasil penampang IP pada gambar 5 (atas) menunjukkan nilai yang cukup bervariasi. Untuk mempermudah dalam menentukan perlapisan, digunakan data pengukuran resistivity pada gambar 5 (bawah). Lapisan pertama memiliki nilai chargeabilitas yang rendah $(0.00240-0.302 \mathrm{msec})$ yang ditunjukkan oleh warna biru. Apabila dibandingkan dengan data resistivitas maka terlihat dengan cukup jelas bahwa lapisan pertama memiliki kedalaman 0.6-3 meter dengan nilai resistivitas yang cukup tinggi (6.81-63.1 ohm.m). Lapisan pertama dapat diidentifikasi berupa lapisan akifer lempung pasiran (garis merah). Apabila dibandingkan dengan penampang IP maka terlihat bahwa pada pada kedalaman 0.6-3 meter memiliki nilai yang rendah (mendekati nol). Nilai tersebut kemungkinan besar merupakan nilai chargeabilitas air. Jadi dapat diduga kuat lapisan tersebut merupakan lapisan akifer. Dibagian tengah sampai timur laut (L1) didominasi oleh nilai resistivitas yang cukup rendah. 

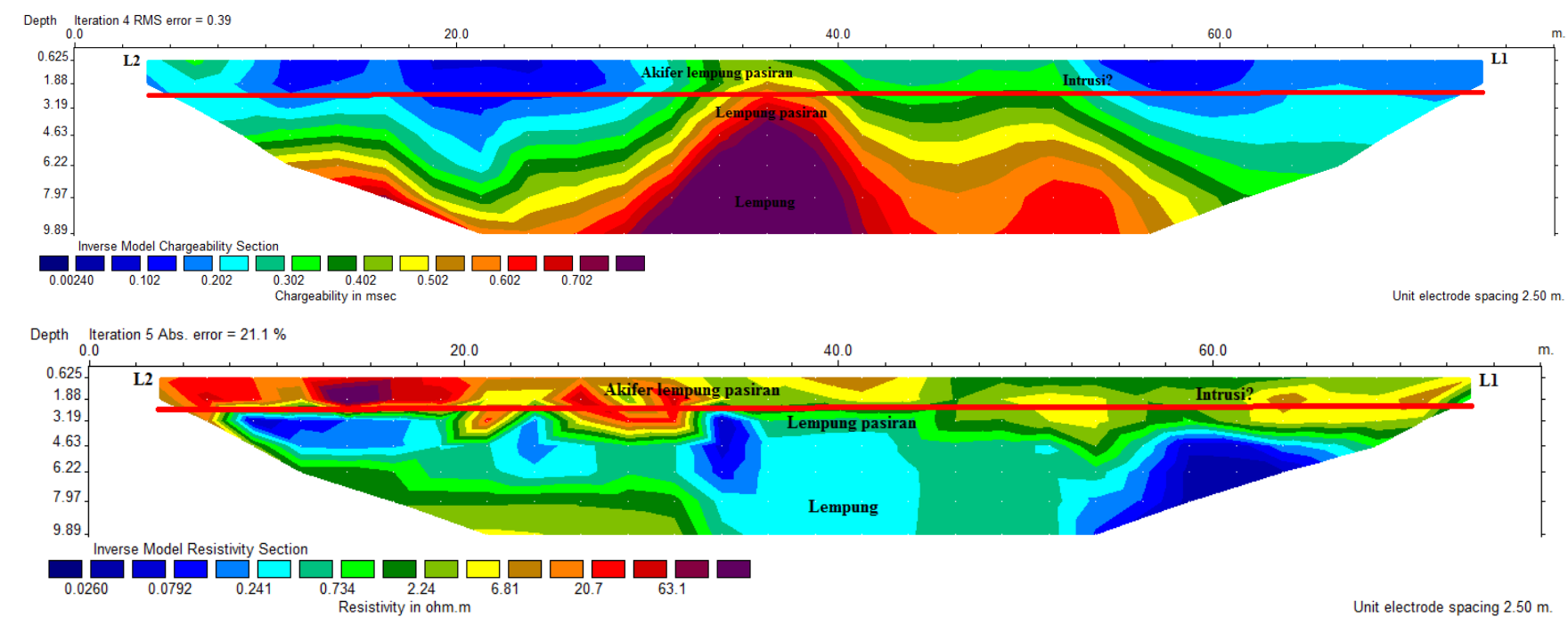

Gambar 5. Hasil penampang IP (atas), resistivity (bawah)

Hal ini kemungkinan merupakan intrusi air laut dari arah utara. Hal ini juga diperkuat oleh data chargeability yang memiliki nilai yang rendah $(0.202 \mathrm{msec})$. Mengingat bahwa daerah Sutorejo merupakan daerah yang berdekatan dengan pantai, tentunya ini memungkinkan bahwa air laut sudah mengintrusi air tanah. Intrusi air laut dapat disebabkan karena pengambilan air tanah yang berlebihan tanpa adanya feedback yang seimbang. Dibawah lapisan pertama merupakan lapisan lempung pasiran dengan kedalaman 3-8 meter (ketebalan 5 meter). Lapisan lempung pasiran ini memiliki nilai chargeabilitas yang cukup tinggi $(0.302-0.702 \mathrm{msec})$. Sedangkan resistivitasnya memiliki nilai rendah $(0.0260-0.734$ ohm.m). Lapisan ketiga terletak pada kedalaman 8 meter memiliki nilai chargeabilitas tinggi $(0.702-1.30 \mathrm{msec})$ dan resistivitas sedang (0.734-6.81 ohm.m). Lapisan ketiga dapat diidentifikasi sebagai lapisan lempung.

\section{KESIMPULAN}

Kesimpulan yang didapat dari penelitian ini.

1. Metode IP dapat mengidentifikasi zona akifer dengan cukup baik. Nilai IP yang rendah (0.00240-0.302 msec) kemungkinan besar adalah akifer air tanah. Nilai IP yang cukup tinggi (0.302 msec) pada akifer kemungkinan besar merupakan intrusi air laut.

2. Model penampang resistivity mengidentifikasi perlapisan dengan baik. Nilai resistivity yang tinggi pada lapisan pertama (6.81-63.1 ohm.m) kemungkinan besar merupakan akifer air tanah. Hal ini akan sesuai apabila dikorelasikan dengan penampang IP.
[1] UNdata. (2010). UNSD Demographic Statistics. Retrieved from UNdata: http://data.un.org

[2] Hakim, A. (2015, Oktober 26). Menggali "Mutiara" di Pesisir Kenjeran Surabaya. Retrieved from Antara Jatim: http://www.antarajatim.com

[3] Telford, W. M. (1990). Applied Geophysics Second Edition. Melbourne: Cambridge University Press.

[4] Sharma, P. V. (1997). Enviromental and Engineering Geophysics. Cambridge: Cambridge University Press.

[5] Priambodo, I. C., Purnomo, H., Rukmana, N., \& Juanda. (2011). Aplikasi Metoda Geolistrik Konfigurasi Wenner-Schlumberger pada Survey Gerakan Tanah di bajawa, NTT. Pusat Vulkanologi dan Mitigasi Bencana Geologi, 1-10. 